\title{
Expression Of BMP7 In Ovarian Cancer And Biological Effect Of BMP7 Knockdown On Ovarian Cancer Cells
}

This article was published in the following Dove Press journal: OncoTargets and Therapy

\author{
Hongwei Guan',* \\ Juan $\mathrm{Li}^{1} *$ \\ Rui Sun' \\ Wei Liu' \\ Mei Feng ${ }^{2}$ \\ $\mathrm{Hui} \mathrm{Ma}^{3}$ \\ Changzhong $\mathrm{Li}^{\prime}$
}

'Department of Obstetrics and Gynecology, Shandong Provincial Hospital affiliated to Shandong University, Jinan, People's Republic of China;

${ }^{2}$ Central Laboratory, Shandong Provincial Hospital Affiliated to Shandong University, Jinan, People's Republic of China; ${ }^{3}$ Shandong University of Traditional Chinese Medicine, Jinan, People's Republic of China

*These authors contributed equally to this work
Purpose: The aim of our research was to investigate the expression of BMP7 in ovarian cancer (OC) and the biological effect of knocking down BMP7 on ovarian cancer A2780 cells.

Methods: We detected BMP7 expression in ovarian cancer and normal ovarian tissue by immunohistochemistry (IHC). We downregulated BMP7 expression using lentivirusmediated RNAi and then examined the effects of knocking down BMP7 on the cell growth and invasion, cell cycle and paclitaxel sensitivity of A2780 cells. The mRNA and protein levels were detected by total RNA extraction and quantitative real-time polymerase chain reaction (qRT-PCR) and Western blotting, respectively. Cell proliferation was measured by CCK-8 and colony formation assays. The number of cells in each cell cycle stage and those undergoing apoptosis were measured by flow cytometry.

Results: BMP7 expression was significantly higher in the ovarian cancer tissues than it was in the normal ovarian tissues. Knocking down BMP7 in ovarian cancer A2780 cells inhibited cell proliferation, migration and invasion; led to G1 cell cycle arrest; and reversed the epithelial-mesenchymal transformation (EMT) process. In addition, downregulating BMP7 increased the sensitivity of the A2780 cells to paclitaxel. Moreover, BMP7 downregulation resulted in decreased expression of Smad1/5/9, p-Smad1/5/9, ID2 and cyclin D1 protein.

Conclusion: The results presented here are expected to contribute to the development of possible therapeutic targets for patients with ovarian cancer.

Keywords: BMP7, ovarian cancer, EMT, drug sensitivity, proliferation, cell cycle

\section{Introduction}

Ovarian cancer is one of the most common and fatal gynecological malignancies in women, with more than 295,000 new cases diagnosed and more than 184,000 deaths attributed to it in women worldwide in 2018. ${ }^{1}$ High recurrence rates and widespread metastasis lead to high mortality for ovarian cancer patients. ${ }^{2}$ Because there are no obvious symptoms in the early stage, the early diagnosis rate of ovarian cancer is low; ovarian cancer is often diagnosed at an advanced stage. ${ }^{3}$ The main treatments for ovarian cancer are surgery and chemotherapy. However, most ovarian cancer patients develop resistance to chemotherapy and relapse, eventually dying from ovarian cancer. ${ }^{4}$ Therefore, it is necessary to find a new strategy to improve the sensitivity of ovarian cancer to chemotherapy.

Bone morphogenetic proteins (BMPs), among the members of the transforming growth factor- $\beta$ superfamily, were found to strongly induce endochondral osteogenesis. ${ }^{5}$ BMPs constitute a group of functional proteins that are widely involved in regulating the
Correspondence: Changzhong $\mathrm{Li}$ Department of Obstetrics and Gynecology, Shandong Provincial Hospital affiliated to Shandong University, 324 Jingwuweisi Road, Jinan 25002I, People's Republic of China

$\mathrm{Tel}+86531 \mathrm{I} 168888909$

Email15168888909@I63.com 
biological processes of proliferation, differentiation and apoptosis of a variety of cells. BMPs play important roles in the invasion and metastasis of cancer. ${ }^{6}$ To date, more than 20 bone morphogenetic proteins have been identified. ${ }^{7}$ BMP activity is initiated through binding to a serine/threonine kinase type I or type II receptor. ${ }^{8}$ Type I serine/threonine kinase receptors include activin-like kinase (ALK)2, 3, and 6; BMPRII, ActRIIA and ActRIIB are type II receptors. BMPs and their receptors have been found to be widely expressed in tumours, such as those in prostate, breast and ovarian cancer. ${ }^{9-11}$

BMP7, also known as osteogenic protein-1(OP-1), is one of the most characteristic osteogenic factors. It has been reported to induce cartilage and bone formation in animal models and promote bone repair in clinical studies. ${ }^{12-14}$ When binding to BMPRII, BMP7 is poised to bind to the type I receptor. The receptor-regulated Smads (R-Smads) are Smad1/5/8, also known as Smad1/5/9, which are phosphorylated and then enter the nucleus with Smad4, where they regulate multiple target genes, such as the inhibitor of DNA binding/differentiation 2(ID2). ${ }^{15}$

The epithelial-mesenchymal transformation is an important process in embryonic development and has been widely recognized in tumour progression in recent years. ${ }^{16,17}$ For many types of epithelial carcinoma, EMT-derived cancer cells are prone to invasion and metastasis. ${ }^{18}$ According to previous research evidence, BMP7 overexpression can enhance the invasion and metastasis of various malignant tumours, such as breast cancer, ${ }^{19}$ prostate cancer ${ }^{20}$ and oesophageal cancer. $^{21}$

In a previous study, it was reported that the BMP7 gene was overexpressed in chemotherapy-resistant ovarian cancer tissues or cells. ${ }^{22}$ Nevertheless, the expression of BMP7 in ovarian cancer and normal ovarian tissues and the effect of BMP7 on the invasion and chemotherapy sensitivity of OC cells remain unclear. In this study, we explored the expression level of BMP7 knockin ovarian cancer tissues and the influence of BMP7 knockdown on the cell proliferation, motility, cell cycle distribution and Taxol sensitivity of A2780 cells, as well as changes in the expression of R-Smad and ID2 protein.

\section{Materials And Methods}

\section{Clinical Specimens}

With the informed written consent of the patient, samples from 55 patients with human ovarian cancer and 40 from patients with normal ovarian tissue were collected from 2015 to 2018 through the Pathology Department of Shandong Provincial Hospital, and after being embedded in paraffin-, the tissue samples were examined by the pathology department to confirm the diagnosis. All patients with ovarian cancer had received no preoperative treatment. This study was approved by the ethics committee of Shandong Provincial Hospital affiliated to Shandong University (protocol no. 2015-042 issued on 3 March 2015). The study was performed in accordance with the principles of the Declaration of Helsinki of the World Medical Association.

\section{Immunocytochemistry}

Paraffin-embedded sections (5 $\mu \mathrm{m}$ thick) were examined through immunohistochemistry (IHC). The paraffinembedded sections were dewaxed and rehydrated using xylene (100\%) and a descending ethanol series (75-100\%). Subsequently, the antigens were retrieved with sodium citrate ( $\mathrm{pH}$ 6.0) using a pressure cooker ( $2 \mathrm{~min}$ ). Then, $3 \% \mathrm{H}_{2} \mathrm{O}_{2}$ was used to block endogenous peroxidase activity in the tissue samples for $30 \mathrm{~min}$ at room temperature. The tissue sections were incubated with rabbit anti-BMP7 antibody (Abcam) at a 1:200 dilution overnight at $4^{\circ} \mathrm{C}$. On the following day, the tissue sections were incubated with horseradish-conjugated secondary antibodies (ZSGB-Bio, Beijing, China). The tissue sections were stained with 3,3'-diaminobenzidine (DAB) and hematoxylin. Brown granules in the cytoplasm or stroma were regarded as indications of positive BMP7 expression. The staining intensity was classified as $0-3(0=$ negative staining, $1=$ low staining intensity, $2=$ moderate staining intensity, and $3=$ high staining intensity), whereas the percentages of positively stained cells were scored as $0-4(0=0 \% ; 1 \leq 25 \%$; $2 \leq 50 \% ; 3 \leq 75 \% ; 4 \leq 100 \%) .{ }^{23}$ Histological scores were calculated by adding both scores. For statistical analysis, scores $0-3$ were regarded as indicating low BMP7 expression, while scores 4-7 were regarded as indicating high BMP7 expression.

\section{Cell Culture}

The human ovarian cancer cell line A2780 was purchased from the Cell Bank of Chinese Academy of Sciences (Beijing, People's Republic of China). Cells were incubated at $37^{\circ} \mathrm{C}$ with $5 \% \mathrm{CO}_{2}$ in RPMI 1640 medium (Gibco BRL, Rockville, MD) supplemented with $10 \%$ heated-inactivated fetal bovine serum (FBS, Biological Industries, Kibbutz Beit HaEmek, Israel) and $1 \%$ penicillin-streptomycin (Macgene, Beijing, People's Republic of China).

\section{Lentivirus Transfection}

The lentivirus vector for the BMP7 knockdown (NM_001719) was generated by cloning small hairpin RNAs (shRNAs) using a self-inactivating lentivirus vector containing a CMV- 
driven GFP reporter and a U6 promoter (GeneChem, Shanghai, People's Republic of China), described herein as sh-BMP7. The target sequence for BMP7 was 5'GGATCTACAAGGACTACAT-3'. According to the instructions, the A2780 cells were seeded at a density of 5,000 cells per well in a 96-well plate and incubated overnight. The cells were transfected with the lentivirus vector at a multiplicity of infection (MOI) of 100. After $24 \mathrm{~h}$, the transfection mixture was replaced with normal complete growth medium to avoid cell toxicity. After $72 \mathrm{~h}$, the transfection efficiency was monitored using an ImageXpress Micro Confocal system and confirmed by quantitative reverse transcription-polymerase chain reaction and Western blot analyses. To generate stable cell-transfected lines with sh-BMP7, the cells were selected with $2 \mu \mathrm{g} / \mathrm{mL}$ puromycin for 5 days. When the observed GFP expression reached $95 \%$, the A2780 cells stably expressing shBMP7 and a negative control (sh-NC) were used in the cell experiments.

\section{Western Blotting}

Target cells were lysed on ice using radioimmunoprecipitation assay (RIPA) lysis buffer with phenylmethylsulfonyl fluoride (PMSF) and a phosphatase inhibitor cocktail, which is a serine protease inhibitor (100:1:1). The protein concentrations were determined using a bicinchoninic acid protein assay kit (Solarbo, Beijing, People's Republic of China). The proteins (30 or $60 \mu \mathrm{g}$ ) subjected to $10 \%$ or $12 \%$ sodium dodecyl sulfatepolyacrylamide gel electrophoresis (SDS-PAGE) and then transferred onto a polyvinylidene difluoride (PVDF) membrane. The membranes were blotted with primary antibodies overnight at $4{ }^{\circ} \mathrm{C}$. The following primary antibodies were used: rabbit anti-BMP7 (1:1,000), rabbit anti-Smad1/5/9 (1:1,000), rabbit anti-Snail+Slug (1:1,000), rabbit anti-cyclin D1 $(1: 10,000)$, rabbit anti-Vimentin $(1: 1,000)$, rabbit anti-NCadherin (1:5,000), rabbit anti-E-Cadherin (1:5,000) (all from Abcam, San Francisco, CA), rabbit anti-ID2 (1:1,000), rabbit-p-Smad1/5/9 (1:1,000) (both from CST, Boston, MD) and rabbit anti-GAPDH, mouse anti- $\beta$-Actin $(1: 2,000)$ (Proteintech, Wuhan, People's Republic of China). The membranes were then incubated with horseradish peroxidase-conjugated secondary antibodies (1:5,000, Proteintech). Positive labelling of the proteins on the membranes was visualized using enhanced chemiluminescence (Amersham Imager 600).

\section{Total RNA Extraction And Quantitative Real-Time Polymerase Chain Reaction}

Total RNA was extracted from sh-BMP7 and sh-NC A2780 cells using the RNAiso Plus extraction reagent (TaKaRa bio,
Inc., Otsu, Japan) and then reverse transcribed into cDNA using a PrimeScript RT reagent kit with gDNA Eraser (TaKaRa). The qPCR experiment was performed using a Light Roche 480 System. The qPCR reaction mixture volume was $20 \mu \mathrm{l}$, which comprises $10 \mu \mathrm{l}$ of TB GreenPremix Ex Taq II (TaKaRa), $0.8 \mu$ l of forward primer $(10 \mu \mathrm{M}), 0.8 \mu \mathrm{l}$ of reverse primer $(10 \mu \mathrm{M})$, and $6.4 \mu \mathrm{l}$ of DEPC water. The relative expression levels of BMP7 and ID2 were evaluated using the $2^{-\Delta \Delta C t}$ method. The following primer sequences were used in the study: BMP7-F: 5'CTCTGGCCAGCCTGCAAGATA-3', BMP7-R: 5'-CCGG AACTCTCGATGGTGGA-3'; ID2-F： 5'-CAACACGGAT ATCAGCATCCTGTC-3', ID2-R: 5'-AC ACAGTGCTTTG CTGTCATTT G-3'; and ACTB-F: 5'-TGGCACCCAGCA CAATGAA-3', ACTB-R:5'-CTAAGTCATAGTCCGCCT AGAAGCA-3'.

\section{CCK-8 Cell Proliferation Assay}

The cells in the logarithmic growth phase were seeded into 96-well plate at a density of 5,000 cells per well. Then, the cells were incubated for 24,48 and $72 \mathrm{~h}$, and $10 \mu \mathrm{L}$ of Cell Counting Kit-8 solution (Dojindo, Kumamoto, Japan) was added to each well. After incubation for $2 \mathrm{~h}$ at $37^{\circ} \mathrm{C}$, the absorbance was measured using a microplate reader (EL340, Bio-Tek Instruments, MA, USA) at $450 \mathrm{~nm}$.

\section{Colony Formation Assay}

Cells were seeded in a 6-well plate at 300 cells/well. After 10 days of incubation at $37^{\circ} \mathrm{C}$ with $5 \% \mathrm{CO}_{2}$, the colonies were fixed with $4 \%$ paraformaldehyde for $30 \mathrm{~min}$ and stained with $0.1 \%$ crystal violet for $10 \mathrm{~min}$ at room temperature. Then, the colonies were counted using Image Pro Plus software.

\section{Immunofluorescence}

Cell slides were rinsed with PBS 3 times for 5 min each time and then fixed with $4 \%$ paraformaldehyde for $30 \mathrm{~min}$. The cells were then washed with PBS (3 times for $5 \mathrm{~min}$ ) and incubated with $0.1 \%$ Triton at room temperature for $10 \mathrm{~min}$. The cells were sealed with goat serum at room temperature for $60 \mathrm{~min}$, and the primary antibody (rabbit anti-BMP7 or rabbit anti-pSmad1/5/9, diluted with goat serum at 1:100) was added and incubated at $4^{\circ} \mathrm{C}$ overnight. On the second day, the cells were reheated and maintained at room temperature for $30 \mathrm{~min}$, washed with PBS (3 times for $5 \mathrm{~min}$ ), incubated with fluorescence secondary antibody at room temperature for $60 \mathrm{~min}$, and washed with PBS (3 times for $5 \mathrm{~min}$ ). The nuclei were stained with DAPI for $10 \mathrm{~min}$ and washed with PBS (3 times for 5 min). Finally, the tablets were sealed with an anti-fluorescence 
quenching agent and observed under a fluorescence microscope.

\section{Transwell Assay}

Migration assay was performed using transwell chambers. A total of $5 \times 10^{4}$ cells were plated in the top wells without serum medium, while medium containing $15 \%$ FBS was added to the bottom well chambers. The cells were incubated for $24 \mathrm{~h}$, and then, cells on the upper wells were gently removed by a cotton swab. The cells that had migrated to the bottom surface of the membrane were fixed with methanol and stained with hematoxylin. The number of invading cells was quantified under a light microscope using three random fields at a magnification of $200 \times$. Invasion assay was performed using transwell chambers that were precoated with Matrigel matrix (RPMI 1640:Matrigel matrix=7:1) (BD Biosciences, Bedford, MA, USA). Each invasion assay group comprised $5 \times 10^{4}$ cells plated in the upper well, and the cells were incubated for $48 \mathrm{~h}$, with the remaining steps similar to those of the migration assay.

\section{CCK-8 Toxicity Assay}

The cells in the logarithmic growth phase were seeded into 96-well plate at a density of $1 \times 10^{4}$ cells/well. Next, the cells were incubated for $24 \mathrm{~h}$, and different concentrations of Taxol $(0.05,0.1,0.5,1,2 \mu \mathrm{M})$ were applied to the cells. Twenty-four hours later, $10 \mu \mathrm{L}$ of CCK-8 solution (Dojindo) was added to each well. After the cells were incubated for $2 \mathrm{~h}$ at $37^{\circ} \mathrm{C}$, the absorbance was measured using a microplate reader (EL340) at $450 \mathrm{~nm}$.

\section{Flow Cytometry For Detecting Cell Apoptosis}

Cell apoptosis was detected using flow cytometry with an Annexin V-phycoerythrin (PE)/7-aminoactinomycin D (7AAD) kit (BD Biosciences, NJ, USA) as published in our paper. ${ }^{24}$ The cells and culture media were collected and centrifuged, and the supernatant was discarded. Next, the cells were rinsed with PBS 3 times. The cells were resuspended in $10 \mathrm{mmol} / \mathrm{L}$ binding buffer and incubated with Annexin V-PE/ 7AAD in the dark for $15 \mathrm{~min}$. Groups of 10,000 cells were analysed using a BD LSRFortessa (BD Biosciences).

\section{Flow Cytometry For Determining The Cell Cycle}

The cells were collected and centrifuged for $5 \mathrm{~min}$ at 1500 $\mathrm{rpm}$. The cells were then resuspended in PBS precooled to $4^{\circ} \mathrm{C}$ and centrifuged at $1500 \mathrm{rpm}$ for $5 \mathrm{~min}$ and fixed in $75 \%$ ethanol that was precooled to $-20^{\circ} \mathrm{C}$ cells and maintained overnight at $4^{\circ} \mathrm{C}$. The cells were mixed with PBS and centrifuged for $5 \mathrm{~min}$ at $1500 \mathrm{rpm}$. The cells were then resuspended in PBS and centrifuged. Subsequently, the cells were resuspended in $100 \mu \mathrm{L}$ PBS. Then, $2 \mu \mathrm{L}$ of 1 $\mathrm{mg} / \mathrm{mL}$ RNase (Solarbo, Beijing, People's Republic of China) was added to the resuspension, and the cells were incubated in a water bath at $37^{\circ} \mathrm{C}$ for $40 \mathrm{~min}$. The cells were stained with $100 \mu \mathrm{L}$ propidium iodide (PI) (BD Biosciences, $100 \mu \mathrm{g} / \mathrm{mL}$ ) dyeing liquid for $20 \mathrm{~min}$ without light. The cell cycle was detected by flow cytometry and the distribution of the cells in cell cycle stages was analysed by Modfit software.

\section{Statistical Analysis}

Statistical analyses were performed using GraphPad Prism 8.0 software. Data are presented as the mean \pm standard deviation for at least three independent experiments. Pearson's chisquare test was used to compare differences in the expression levels of BMP7 in ovarian cancer and normal ovarian tissue. Student's t-tests were used to compare the differences between the sh-BMP7 and sh-NC groups. A $P$-value $<0.05$ was considered statistically significant.

\section{Results}

\section{Overexpression Of BMP7 In The Ovarian Cancer Tissue}

As shown by immunohistochemistry, the staining of BMP7 was mainly concentrated in the cytoplasm and stroma of the tissue. BMP7 expression was statistically higher in the ovarian cancer samples than in the normal ovarian specimens $(P<0.05)$ (Figure 1A and B).

\section{Transfection Efficiency Of The Generated Stable Cell Lines}

Cells were transfected and screened, and the expression of GFP was detected using fluorescence microscopy. qRT-PCR, Western blotting and immunofluorescence were used to confirm the transfection efficiency. The results revealed that the BMP7 expression level was significantly lower in the shBMP7 group compared to the level in the sh-NC group. The data indicated that the lentivirus containing the knocked down BMP7 gene was successfully transfected into the A2780 cells (Figure 2A-E). 
A

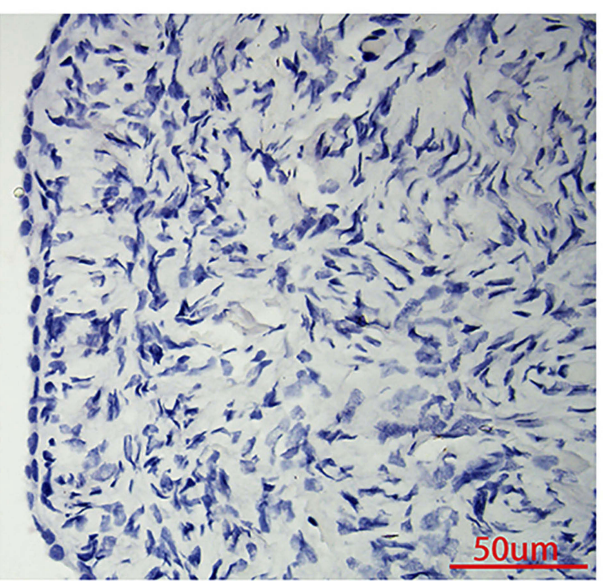

B

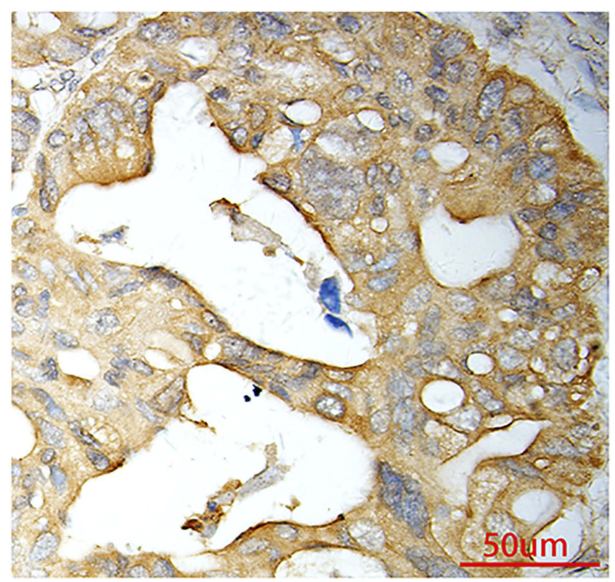

Figure I Expression of BMP7 in human ovarian cancer and normal ovarian tissues. BMP7 expression in (A) normal ovarian and (B) ovarian cancer tissue. BMP7 expression was significantly higher in ovarian cancer tissues than in normal ovarian tissues $(P<0.05)$ (Magnification $400 \times)$.

A sh-BMP7
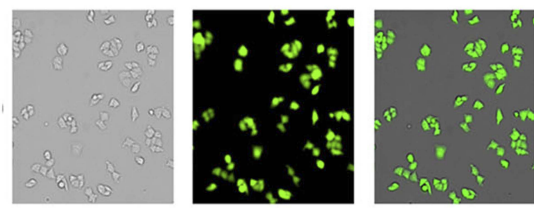

sh-NC
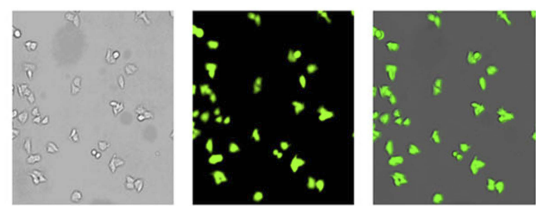

D

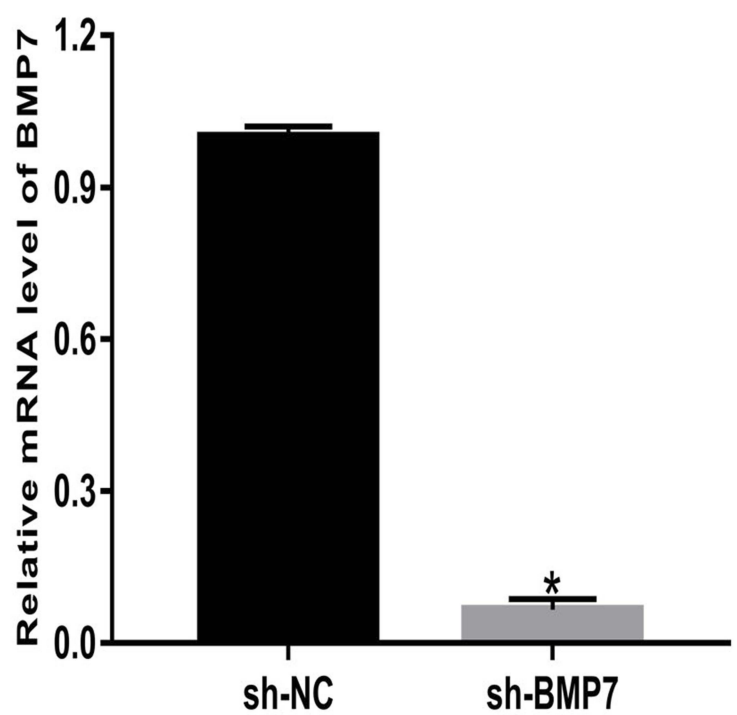

B

BMP7

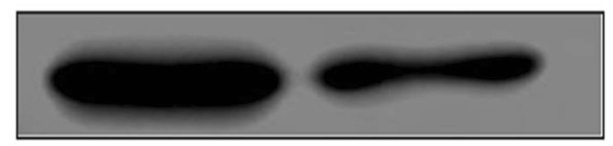

GAPDH

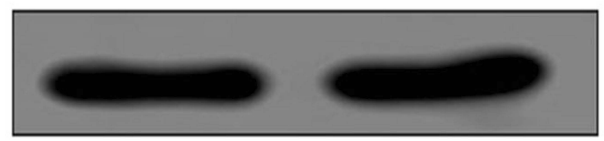

C

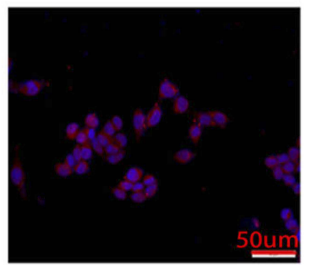

sh-NC

E

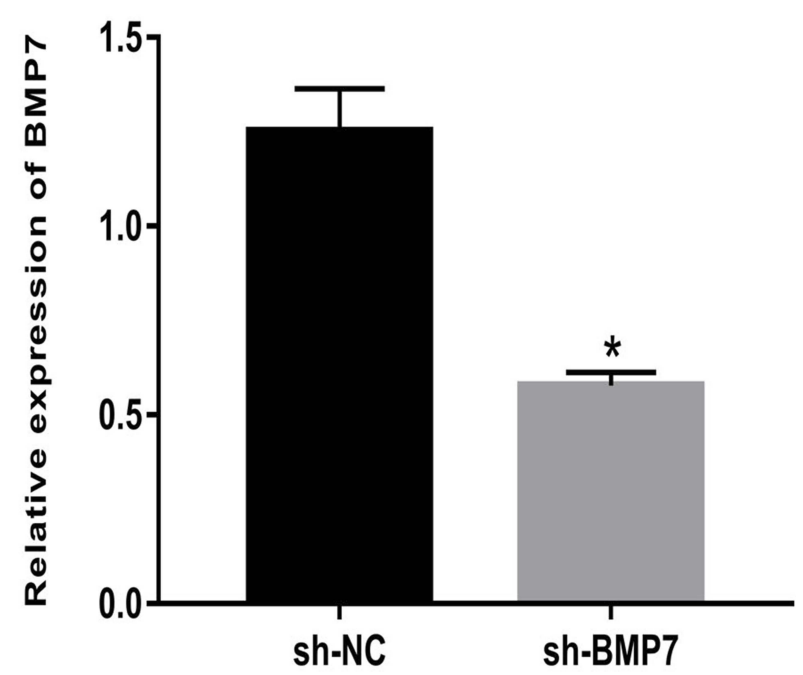

Figure 2 Identification of downregulated BMP7 expression in lentivirus transfection systems. (A) GFP expression was detected in sh-NC and sh-BMP7 A2780 cells by a fluorescence microscope (Magnification 100x). (B and E) BMP7 protein expression was decreased in the A2780 cells transfected with the lentivirus containing BMP7, as determined by Western blotting. (C) BMP7 protein expression was reduced in the sh-BMP7 A2780 cells compared to sh-NC cells, as determined by immunofluorescence (Magnification 400×). (D) BMP7 mRNA level was reduced in the A2780 cells transfected with the lentivirus containing BMP7, as determined by $q$ RT-PCR. *P<0.05. 


\section{BMP7 Promoted The Proliferation Of} The A2780 Cells

The CCK-8 proliferation assay showed that the sh-BMP7 cells exhibited a significant decrease in proliferation compared with that of the sh-NC group (Figure 3A). In addition, the results of the colony formation assay also presented a trend similar to those of the CCK-8 assay in which the colony formation ability was significantly decreased in the sh-BMP7 group cells compared with that of the sh-NC group cells (Figure 3B and C).

\section{Knocking Down BMP7 Reduced The Migratory And Invasive Mobility Of The A2780 Cells}

Transwell assays were conducted to determine the effects of BMP7 on the migration and invasion capacity of the A2780 cells. The migration capacity of the sh-BMP7 A2780 cells was significantly suppressed compared with that of the sh-NC cells (Figure 4A and C). We obtained a similar result for the invasive capacities as for the migration ability: the sh-BMP7 A2780 cells exhibited a markedly reduced level of invasion through the Matrigel compared to that of the sh-NC cells (Figure 4B and D). Hence, these results demonstrated that knocking out BMP7 inhibited the migration and invasion abilities of the A2780 cells.

\section{Effects Of BMP7 On The Major EMT- Related Proteins}

The EMT promotes tumour cell invasion and metastasis. Therefore, we detected changes in the expression of the EMT-related markers to explore the function of BMP7 during the EMT. E-Cadherin is the characteristic protein of the epithelial phenotype that mediates cell-cell interactions. N-Cadherin and Vimentin are commonly used as tumour markers to identify mesenchymal phenotypes. Snail and Slug are transcription regulatory factors that bind to E-box motifs to suppress E-cadherin transcription and regulate EMT. ${ }^{25}$ Analysis using Western

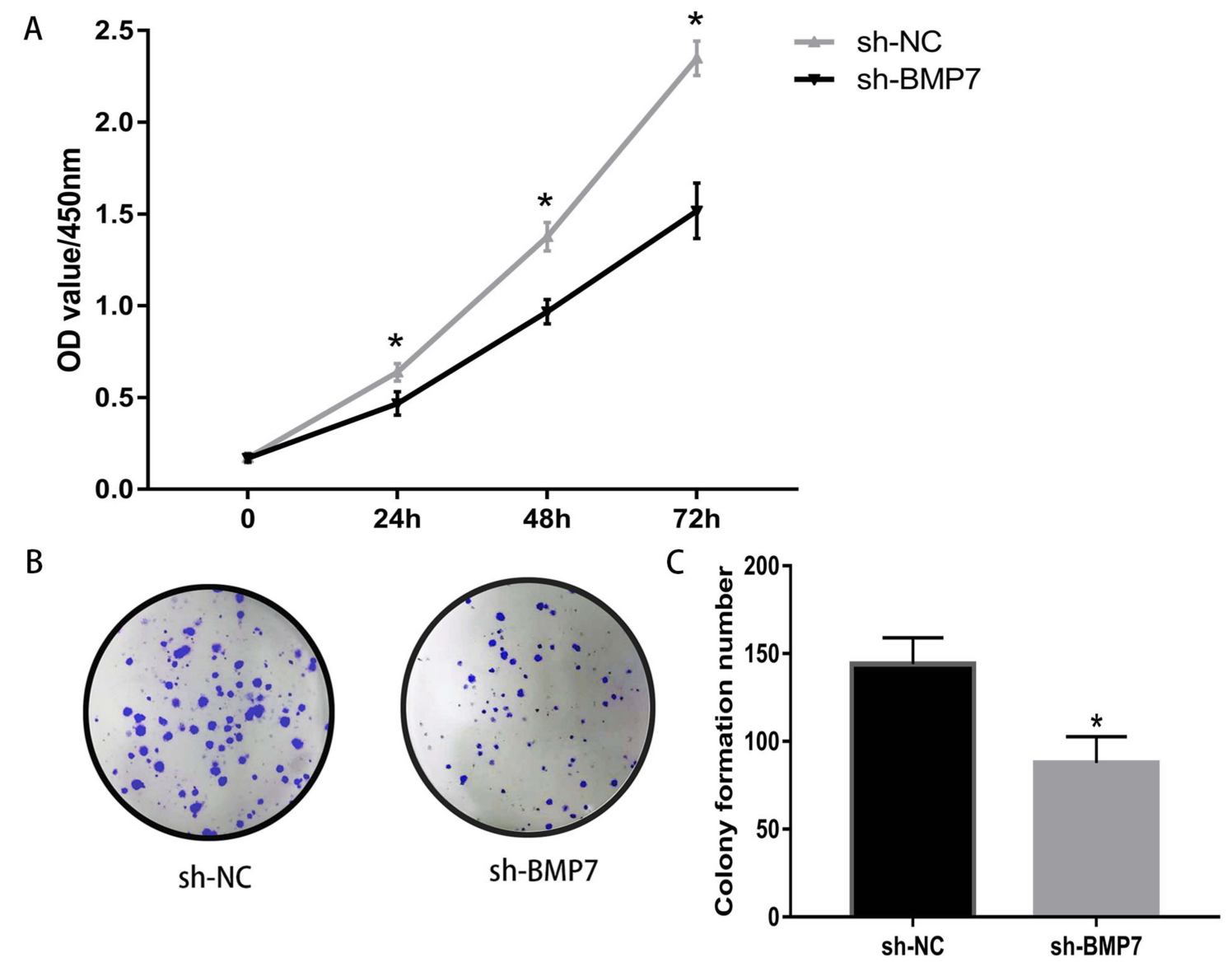

Figure 3 Effect of BMP7 downregulation on the proliferation of A2780 cells. (A) Proliferation curve of the A2780 cells with sh-NC and sh-BMP7. (B and C) The colonyforming abilities of the $A 2780$ cells were inhibited by knocking down BMP7, compared with the ability of the cells in the sh-NC group. $* P<0.05$. 
A

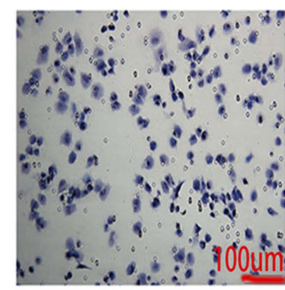

B

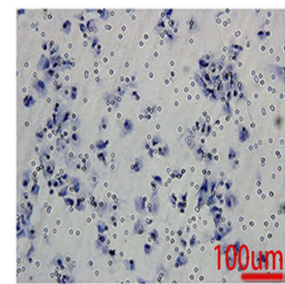

sh-NC
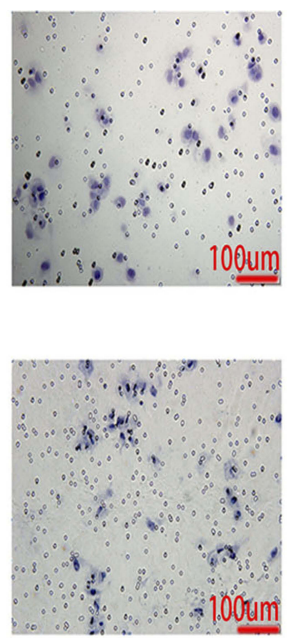

sh-BMP7
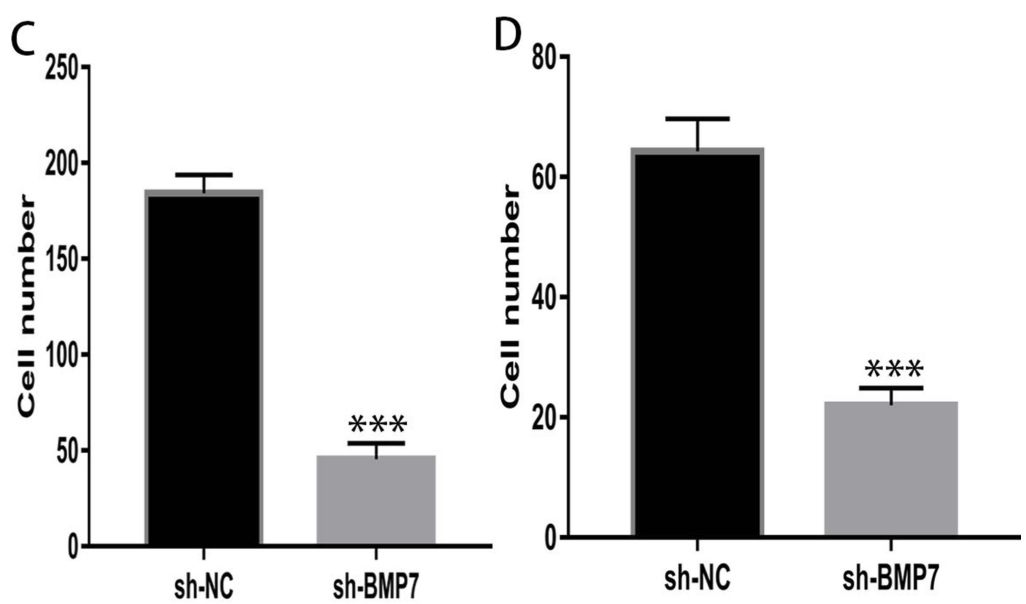

$\mathrm{E}$
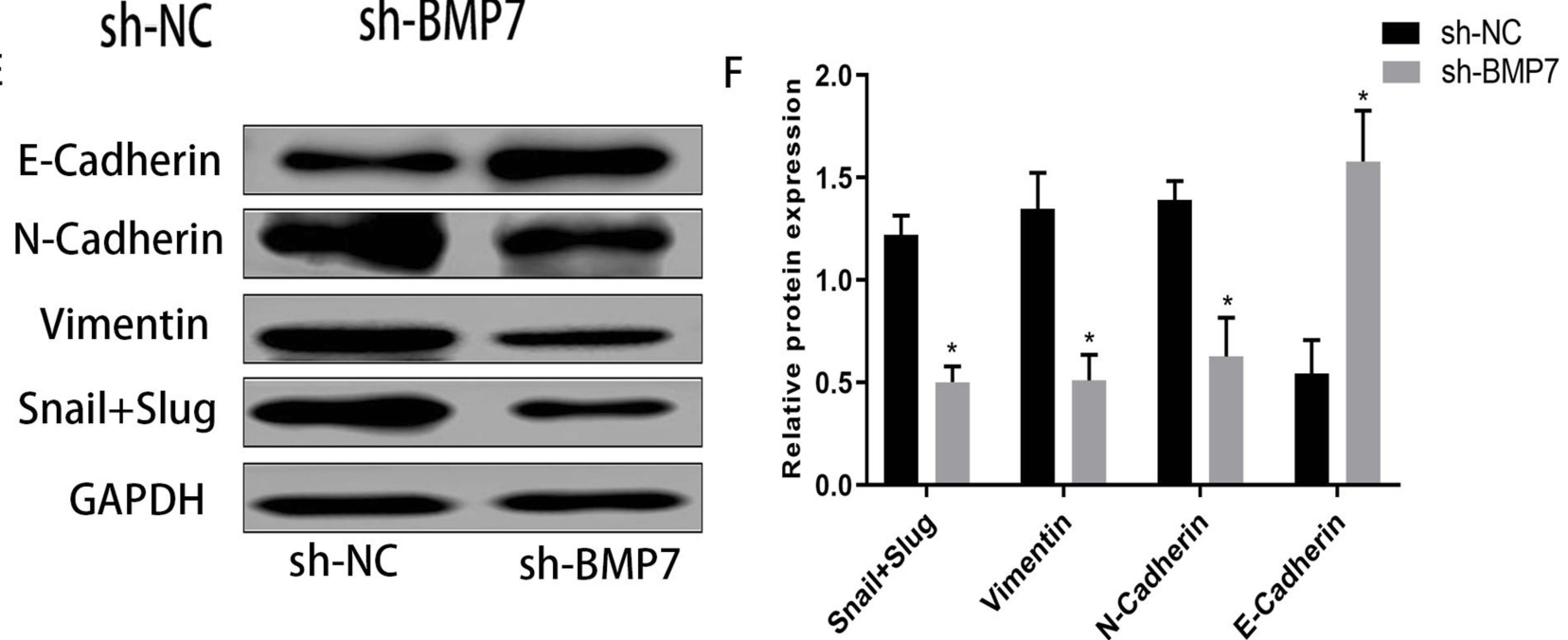

Figure 4 Effects of knocking down BMP7 on A2780 cell migration and invasion abilities and the EMT-related proteins. (A and C) Cell migration ability of the A2780 cells transfected with sh-NC and sh-BMP7 as measured by cell migration assay (magnification 200x). (B and D) Cell invasion ability of the A2780 cells transfected with sh-NC and sh-BMP7 as measured by cell invasion assay (magnification 200x). (E and F) Effect of BMP7 downregulation on the expression of the EMT-related proteins (Snail, Slug, Vimentin, N-Cadherin and E-Cadherin). $* P<0.05$, $* * * P<0.001$.

blotting indicated that the decreased expression of BMP7 in A2780 cells exhibited significantly increased protein levels of E-Cadherin, while the protein levels of $\mathrm{N}$-Cadherin and Vimentin were reduced. Moreover, the protein levels of Snail and Slug were also decreased (Figure 4E and F). As a result, BMP7 could affect several vital EMT-related proteins.

\section{Knocking Down BMP7 Resulted In Decreased Expression Of Smad I/5/9, P- SmadI/5/9 And ID2 Protein}

BMP7 binds to BMP membrane receptors to transduce signals through Smads with non-Smad signalling pathways. ${ }^{26,27}$ As demonstrated by Western blotting, the levels of Smad1/5/ 9, p-Smad1/5/9, and ID2 were markedly reduced in the sh-
BMP7 cell group (Figure 5A, C, E, and F). It was also shown that the expression of $\mathrm{p}$-Smad1/5/9 was decreased in shBMP7 A2780 cells compared with sh-NC A2780 cells by immunofluorescence (Figure 5B). Furthermore, the level of ID2 mRNA was also significantly decreased in sh-BMP7 A2780 cells by qRT-PCR (Figure 5D).

\section{Knocking Down BMP7 Induced GI Cell Cycle Arrest In The A2780 Cells}

Flow cytometry is an important method for detecting the cell cycle. As shown in Figure 6A-D, the proportion of shBMP7 group cells in the G1 phase was significantly increased compared with that of the sh-NC cell group, while the proportion of cells in the $\mathrm{S}$ phase in the shBMP7 group was significantly decreased compared with 


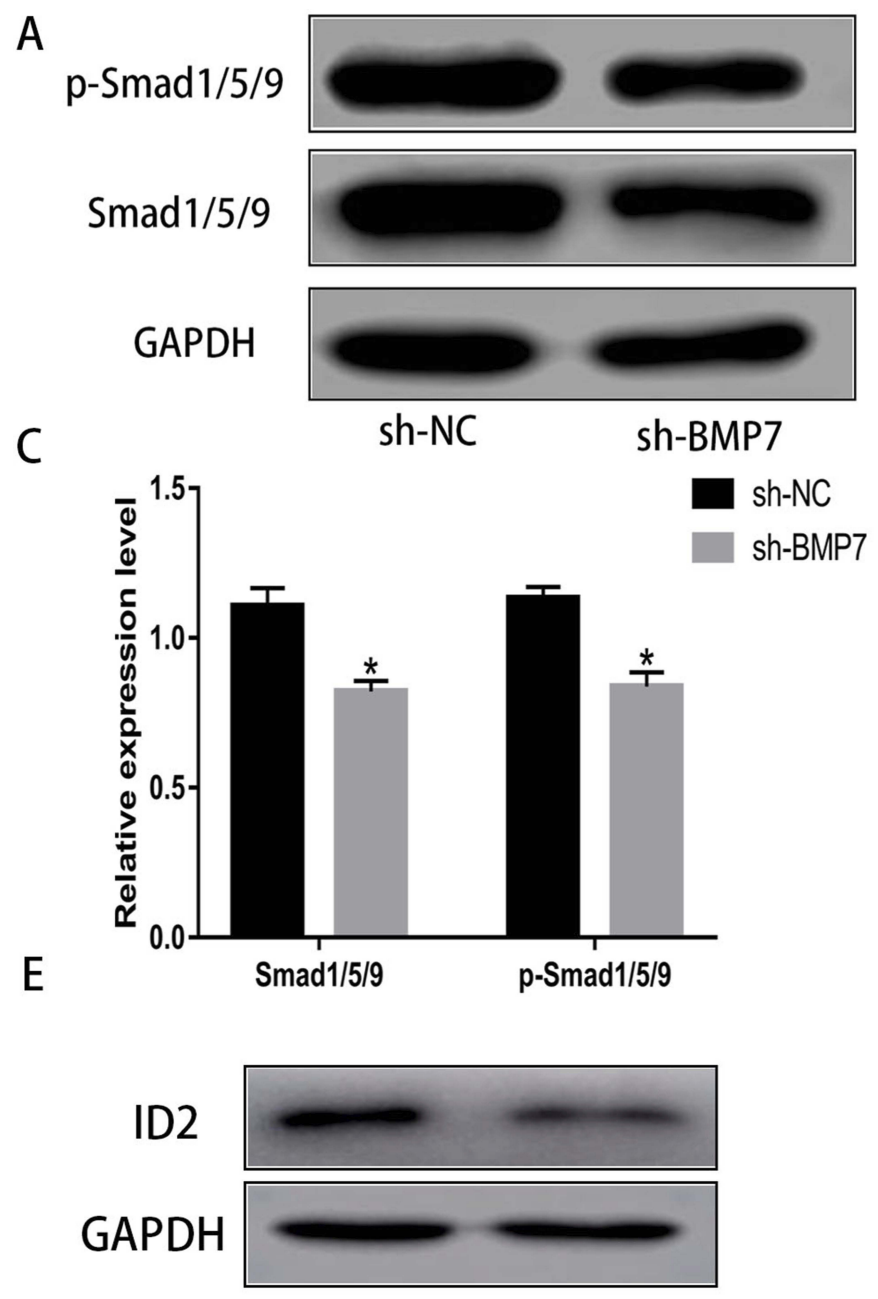

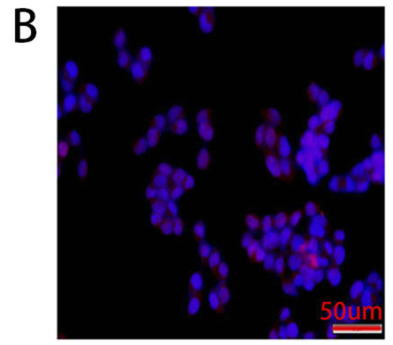

sh-NC
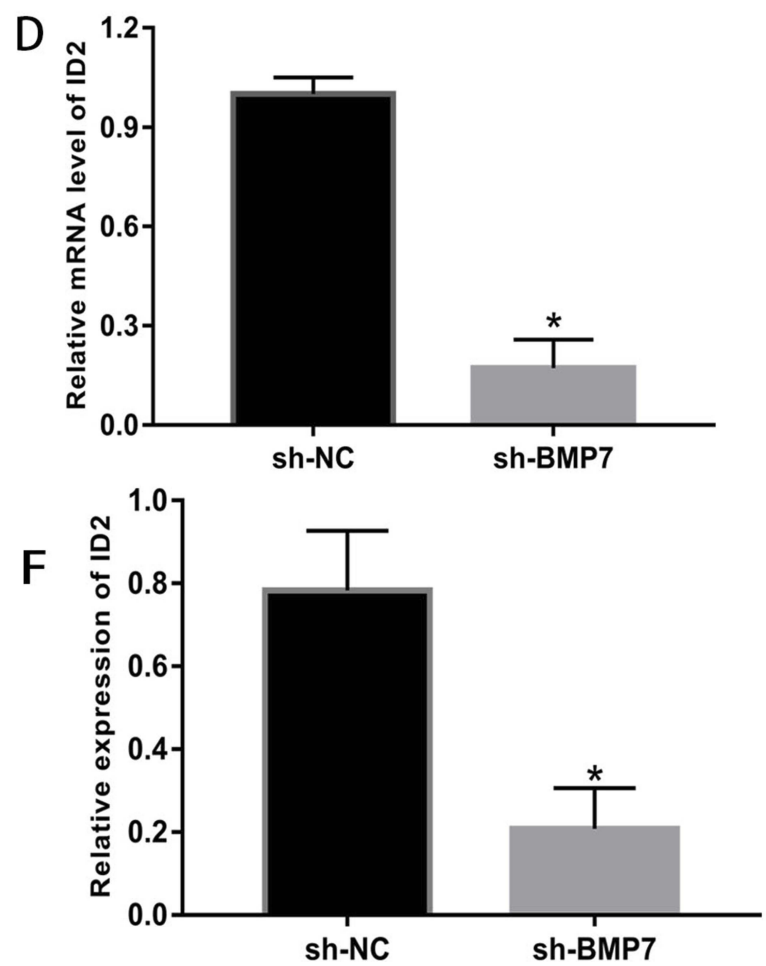

Figure 5 The downregulation of BMP7 resulted in the downregulation of SmadI/5/9, p-SmadI/5/9 and ID2. (A and C) SmadI/5/9 and p-SmadI/5/9 expression levels were reduced in the sh-BMP7 A2780 cells compared with levels in the sh-NC cells, as determined by Western blotting. (B) p-SmadI/5/9 expression was reduced in the sh-BMP7 A2780 cells compared with that in the sh-NC cells, as determined by immunofluorescence (magnification $400 \times$ ). (E and F) The ID2 protein expression was reduced in the sh-BMP7 group compared that in the sh-NC group, as measured by Western blotting. (D) The ID2 mRNA level was decreased in the A2780 cells transfected with sh-BMP7 compared with that of the sh-NC-transfected cells, as determined by qRT-PCR. $* P<0.05$.

that of the sh-NC group. In addition, there was no difference in the proportion of G2 cells between the two groups. In addition, the cyclin D1 level was significantly decreased in the sh-BMP7 group compared with that of the sh-NC group.

\section{Knocking Down BMP7 Increased The Taxol Sensitivity Of The A2780 Cells}

CCK-8 was used to examine cell viability after treatment with different doses of Taxol for $24 \mathrm{~h}$ in the sh-BMP7 and sh-NC A2780 cells. According to the CCK-8 experiment results, when the cells were treated with paclitaxel at different concentrations for $24 \mathrm{~h}$, the relative survival of the sh-BMP7 A2780 cell group was lower than that of the
sh-NC A2780 cell group (Figure 7A). Furthermore, the effect of BMP7 suppression on apoptosis in A2780 ovarian cancer cells was assessed by flow cytometry. The results indicated that the rate of early apoptosis and the rate of apoptosis of cells in the sh-BMP7 group were significantly higher than they were for the cells of the sh-NC group after $24 \mathrm{~h}$ of paclitaxel treatment at a concentration of $2 \mu \mathrm{M}$ (Figure 7B-D).

\section{Discussion}

A previous study reported the upregulation of BMP7 expression in ovarian cancer drug-resistant tissues and cells; ${ }^{22}$ however, the effect of BMP7 on the proliferation, cell cycle and EMT process of ovarian cancer cells and the resistance to 

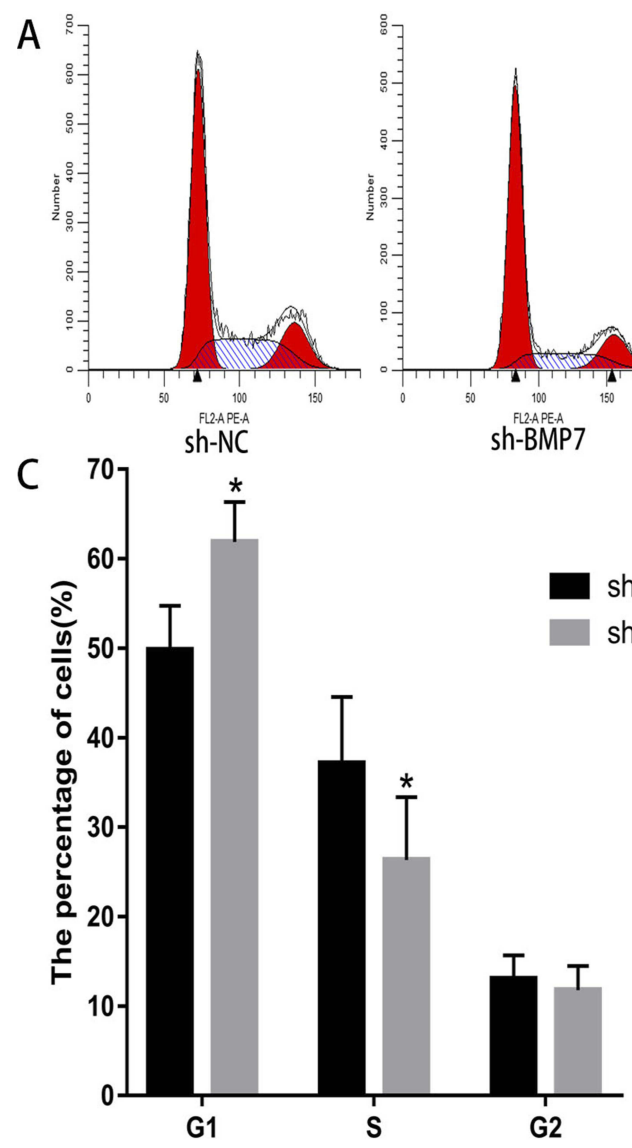

B
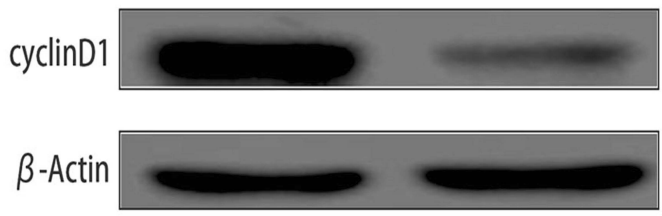

sh-NC

sh-BMP7

D

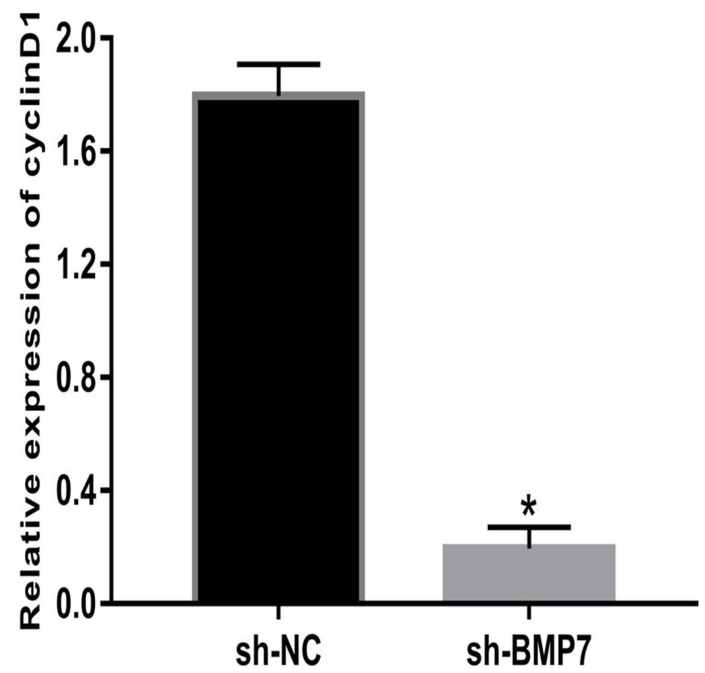

Figure 6 Effect of BMP7 downregulation on A2780 cell cycle. (A and C) BMP7 knockdown led to GI phage arrest in A2780 cells. (B and D) Down-regulation of BMP7 resulted in decreased expression of cyclin DI protein in A2780 cells. $* P<0.05$.

paclitaxel have not been studied. The BMP family includes more than 20 identified members and is widely involved in a variety of biological processes, including bone formation and embryonic development. In recent decades, the multiple roles of BMPs in tumour cell growth, invasion, metastasis and angiogenesis have been extensively investigated. ${ }^{8}$ BMP7 is a pleiotropic signalling molecule that plays an important role in development. It belongs to the bone morphogenetic protein family and has been investigated for its possible contribution to the pathogenesis of cancer. In this study, BMP7 expression was markedly higher in ovarian cancer tissues than in the normal ovarian tissues. In addition, we found that BMP7 can affect cell proliferation, the cell cycle, the EMT process and the sensitivity to paclitaxel in A2780 cells. In our study, it was found that downregulated BMP7 inhibited the proliferation of A2780 cells. This result is similar to a previous study showing that BMP7 silencing inhibited the proliferation of breast cancer BT-474 cells. ${ }^{19}$ In addition, we also found that knocking down BMP7 increased the proportion of the A2780 cells in G1 stage but decreased the proportion of A2780 cells in S stage, which resulted in G1 cell cycle arrest. It was demonstrated that knocking down BMP7 resulted in an increased proportion of BT-474 cells in G1 stage and a decreased proportion of BT-474 cells in S stage. ${ }^{19}$ In A2780 cells, downregulation of BMP7 resulted in decreased expression of cyclin D1. cyclin D1 is a key regulator that plays an important role in the transition of G1 to S stage. ${ }^{28}$ Cyclin D1 promotes cell transition from the $\mathrm{G} 1$ phase to the $\mathrm{S}$ phase, thereby promoting cell division and proliferation. ${ }^{29}$ In our present study, the decreased expression of cyclin D1 may be the cause of the inhibited cell proliferation and the G1 cell cycle arrest. Therefore, we believe that the downregulated cyclin D1 expression caused by knocking down BMP7 may be the mechanism that suppresses the proliferation and leads to the G1 cell cycle arrest of the A2780 cells. The EMT, first discovered by Betty Hay in the 1980s, is well known as a feature of embryogenesis. Later, the EMT was also found to be involved in wound healing, organ fibrosis, and cancer invasion. Primary tumour cells lose E-Cadherin-mediated 
A

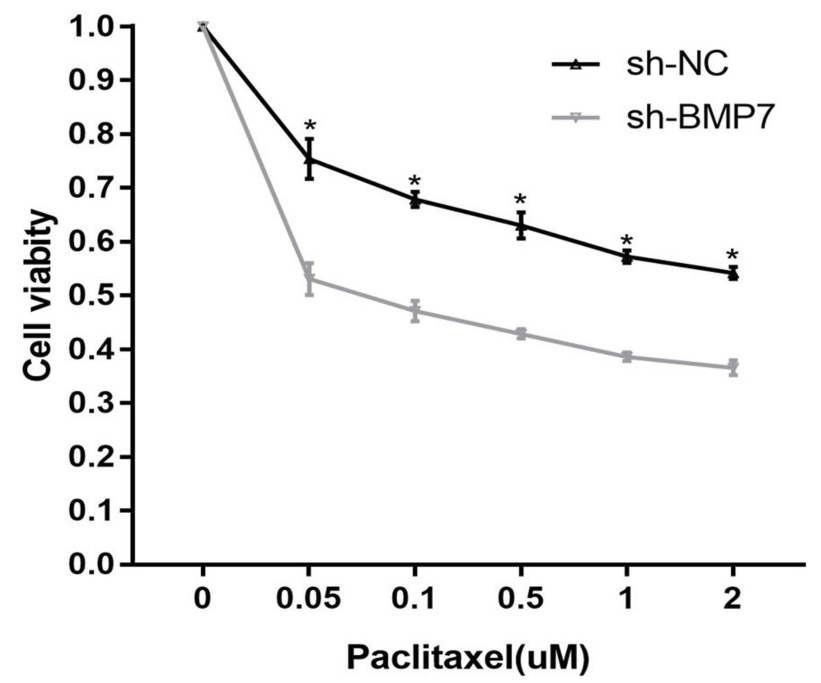

C

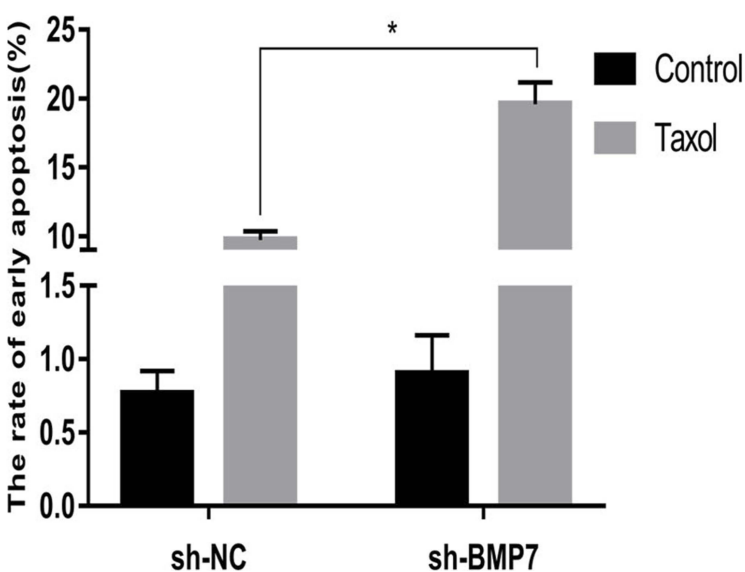

B
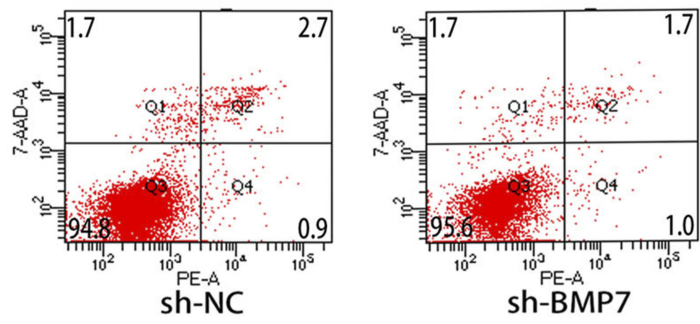

sh-BMP7
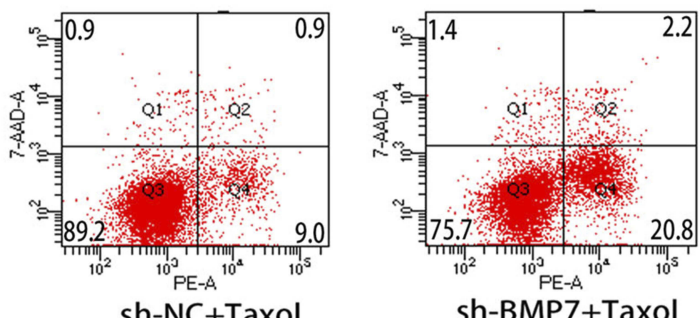

sh-BMP7+Taxol

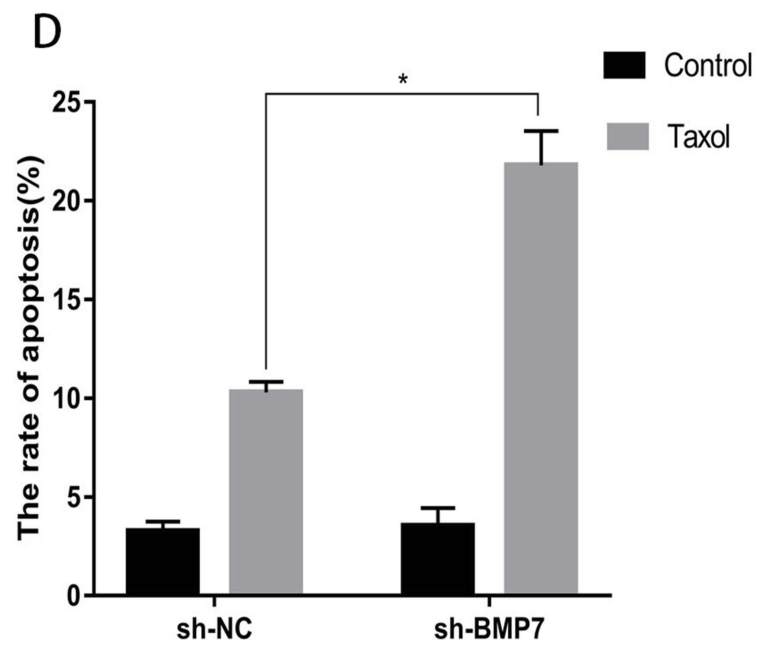

Figure 7 Knocking down BMP7 enhanced the sensitivity of the A2780 cells to Taxol. (A) Under the action of paclitaxel treated at different concentrations, the cell viability of the BMP7-knockdown cell group was lower than that of the sh-NC cell group. (B, C and D) After $24 \mathrm{~h}$ of $2 \mu \mathrm{M}$ paclitaxel treatment, the early apoptosis rate and the apoptosis rate of the sh-BMP7 cell group were significantly higher than those of the sh-NC cell group. $* P<0.05$.

cell adhesion, break through the basement membrane, become more invasive, and penetrate the blood and settle in a new nest. Cells undergoing EMT acquire stem cell-like properties, which increase their potential for tumorigenesis and proliferation. ${ }^{30,31}$ In the present study, we found that BMP7 had an effect on the EMT process in which BMP7 suppression could markedly weaken the invasion and migration ability of A2780 cells and lead to changes in the expression levels of EMT-related proteins. The expression level of E-Cadherin was obviously increased, while the expression levels of N-Cadherin, Vimentin, Snail and Slug were significantly decreased. Previous studies have shown that BMPs are involved in the induction of the EMT, which is characterized by enhanced cell migration and invasion. ${ }^{32}$ Snail and Slug transcription factors can induce EMT by repressing the epithelial marker (E-Cadherin) and activating the mesenchymal phenotype marker (N-Cadherin). ${ }^{25}$ In this study, the downregulated BMP7 could inhibit Snail and Slug expression and reverse the EMT in the A2780 cells. The reduced expression of Snail and Slug resulted in the upregulation of E-Cadherin and the downregulation of N-Cadherin, thus reversing the EMT. This result suggests that downregulating BMP7 reverses the EMT by reducing Snail and Slug expression in the A2780 cells. The A2780 cells with knocked down BMP7 showed lower viability than the sh-NC cells treated with different concentrations of paclitaxel. The apoptosis rate of the BMP7-knockdown cells was significantly increased after paclitaxel treatment compared with that of the sh-NC cells. These results suggest that downregulating BMP7 could increase the sensitivity of ovarian cancer cells to paclitaxel. 
BMP7 is very highly expressed in drug-resistant ovarian cancer cells or tissues. ${ }^{22}$ Similarly, in mantle cell lymphoma, BMP7 expression is increased in patients with drug resistance. When BMP7 is downregulated, the sensitivity of Jeko human lymphoma cells to cytarabine and bortezomib was increased. ${ }^{33}$ BMP7 inhibition was also associated with increased sensitivity to cetuximab in oral squamous cell carcinomas. ${ }^{34}$ These studies suggest that BMP7 is associated with chemotherapy sensitivity. This finding supports our results showing that the downregulated BMP7 increases the sensitivity of ovarian cancer cells to Taxol chemotherapy. In our experiments, we also found that the downstream genes of BMP7, such as Smad1/5/9 and p-Smad1/5/9, were decreased in the BMP7-knockdown A2780 cells. BMP7 binds to the receptor that induces the phosphorylation of $\operatorname{Smad1/5/9}$; then, $\mathrm{p}$-Smad1/5/9 enters the nucleus and regulates transcription factors such as ID2. ${ }^{15}$ Therefore, BMP7 exerts its function in ovarian cancer A2780 cells through the canonical BMP7/Smad1/5/9 pathway. Inhibitors of the DNA binding/ differentiation (ID) proteins negatively regulate basic helixloop-helix (bHLH) transcription factors by forming heterodimers. ${ }^{35}$ It has been shown that the bHLH factors play important roles in different types of tissue-specific differentiation and cellular functions. ${ }^{36}$ ID proteins play a wide range of biological roles in cell proliferation, differentiation, development and tumorigenesis. Four members of the ID protein family, ID1, ID2, ID3, and ID4, have been identified in humans. ${ }^{37}$ Among the ID genes, those of BMPs induce the expression of ID2. ${ }^{38}$ In our study, BMP7 downregulation caused simultaneous downregulation of Smad1/5/9, pSmad1/5/9 and ID2; therefore, we speculate that BMP7 may play a role in ovarian cancer through the BMP7/ Smad1/5/9/ID2 axis, but the specific mechanism remains unclear and further study is required. In human breast and hepatocellular carcinoma, ID2 was able to promote proliferation. ${ }^{39,40}$ In oral squamous cell carcinoma, ID2 was able to enhance the invasion of tumour cells. ${ }^{41}$ It has also been reported that ID2 promotes G1/S cell cycle progression by interacting with non-phosphorylated $\mathrm{pRb}$ to release $\mathrm{E} 2 \mathrm{~F}$ from $\mathrm{pRb}^{42}$ In addition, in acute myeloid leukaemia, high expression levels of ID in bone marrow indicate a poor response to chemotherapy. ${ }^{43}$ In squamous cell carcinoma cells in the neck, overexpressed ID2 leads to decreased sensitivity to cisplatin. ${ }^{44}$ Downregulating ID2 can increase

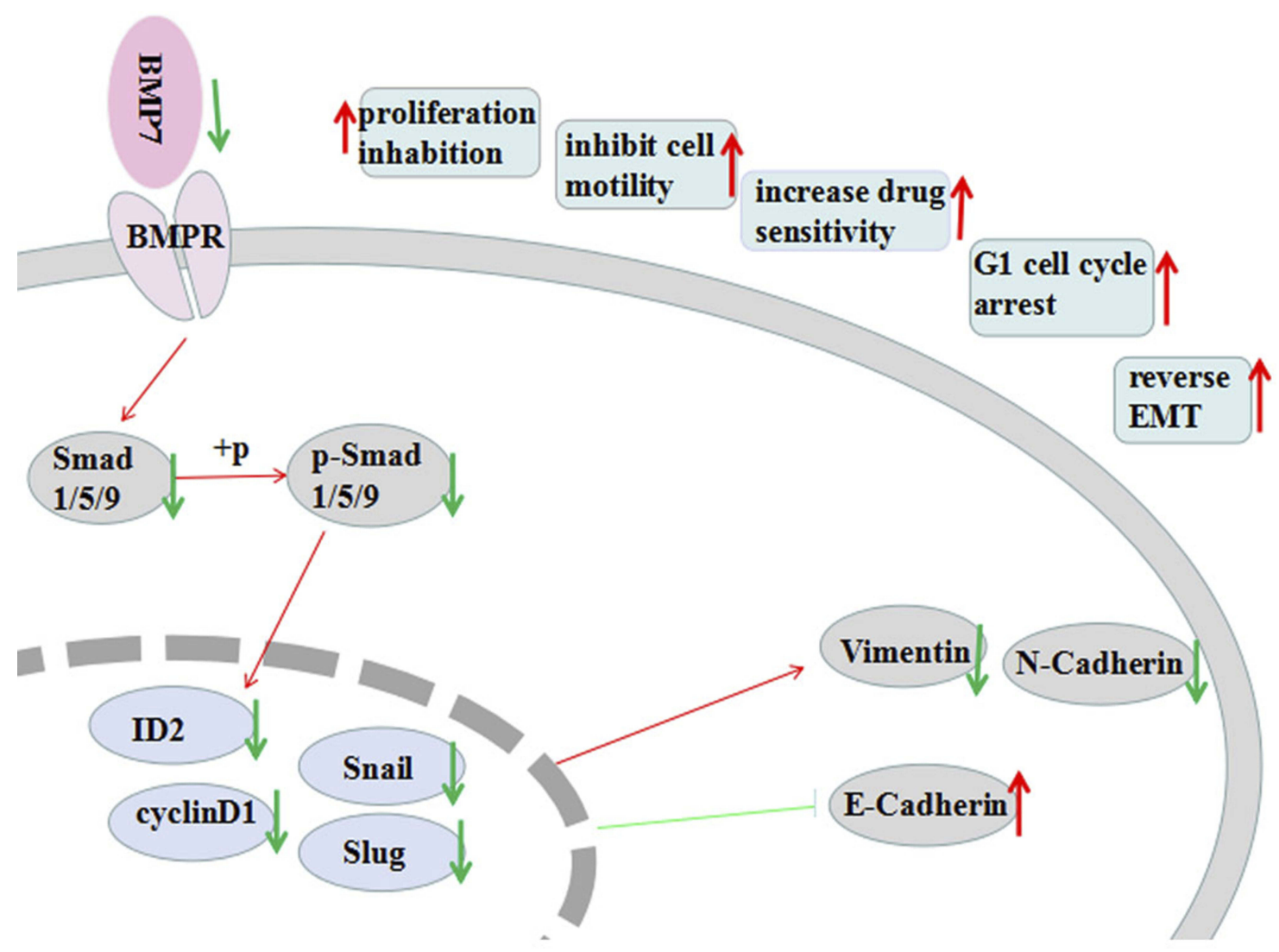

Figure 8 Possible mechanism of BMP7 action in ovarian cancer A2780 cells. 
the sensitivity of glioma cells to chemotherapy. ${ }^{45}$ These findings provide evidence that BMP7 possibly influences ovarian cancer through the BMP7/Smad1/5/9/ID2 axis. In summary, the downregulation of BMP7 in ovarian cancer cells induced a decrease in Smad1/5/9 and ID2 expression, as well as had an impact on cell proliferation, migration, invasion and the sensitivity of cells to chemotherapy. Therefore, we speculate that BMP7 plays a role in ovarian cancer through the BMP7/Smad1/5/9/ID2 pathway (Figure 8).

\section{Conclusion}

In conclusion, knocking down BMP7 in ovarian cancer A2780 cells inhibited cell proliferation, migration, invasion, and led to G1 cell cycle arrest, and increased cell sensitivity to paclitaxel. BMP7 plays these roles through the BMP7/Smad1/5/9 pathway. According to our findings, BMP7 may be a potential therapeutic target for improving the efficiency of ovarian cancer treatment.

\section{Acknowledgments}

This research was funded by the National Nature Science Foundation of China (81503298 and 81671434).

\section{Author Contributions}

All authors contributed to data analysis, drafting or revising the article, gave final approval of the version to be published, and agree to be accountable for all aspects of the work.

\section{Disclosure}

The authors report no conflicts of interest with respect to this work.

\section{References}

1. Bray F, Ferlay J, Soerjomataram I, Siegel R, Torre L, Jemal A. Global cancer statistics 2018: GLOBOCAN estimates of incidence and mortality worldwide for 36 cancers in 185 countries. CA Cancer J Clin. 2018;68:394-424. doi:10.3322/caac.21492

2. Jin $\mathrm{H}$, Yu Y, Zhang T, et al. Snail is critical for tumor growth and metastasis of ovarian carcinoma. Int J Cancer. 2010;126:2102-2111. doi:10.1002/ijc. 24901

3. Cannistra SA. Cancer of the ovary. New Engl J Med. 2004;351:25192529. doi:10.1056/NEJMra041842

4. Ffrench B, Gasch C, O'Leary JJ, Gallagher MF. Developing ovarian cancer stem cell models: laying the pipeline from discovery to clinical intervention. Mol Cancer. 2014;13:262. doi:10.1186/14764598-13-262

5. Rothhammer T, Wild PJ, Meyer S, et al. Bone morphogenetic protein 7 (BMP7) expression is a potential novel prognostic marker for recurrence in patients with primary melanoma. Cancer Biomark. 2007;3:111-117.
6. Heinke J, Kerber M, Rahner S, et al. Bone morphogenetic protein modulator BMPER is highly expressed in malignant tumorsand controls invasive cell behavior. Oncogene. 2012;31:2919-2930. doi:10.1038/ onc. 2011.473

7. Miyazono K, Kusanagi K, Inoue H. Divergence and convergence of TGF-beta/BMP signaling. $J$ Cell Physiol. 2001;187:265-276. doi: $10.1002 /$ jcp. 1080

8. Kawabata M, Imamura T, Miyazono K. Signal transduction by bone morphogenetic proteins. Cytokine Growth Factor Rev. 1998;9:49-61.

9. Yang S, Du J, Wang Z, et al. BMP-6 promotes E-cadherin expression through repressing deltaEF1 in breast cancer cells. BMC Cancer. 2007;7:211. doi:10.1186/1471-2407-7-211

10. Shepherd TG, Nachtigal MW. Identification of a putative autocrine bone morpho- genetic protein-signaling pathway in human ovarian surface epithelium and ovarian cancer cells. Endocrinology. 2003;144:3306-3314. doi:10.1210/en.2003-0185

11. Kim IY, Lee DH, Ahn HJ, et al. Expression of bone morphogenetic protein receptors type-IA, -IB and -II correlates with tumor grade in human prostate cancer tissues. Cancer Res. 2000;60:2840-2844.

12. Ripamonti U, Van Den Heever B, Sampath TK, Tucker MM, Rueger DC, Rddi AH. Complete regeneration of bone in the baboon by recombinant human osteogenic protein-1 (hOP-1, bone morphogenetic protein-7). Growth Factors. 1996;13:273-289. color plates III-VIII, pre bk.

13. Asahina I, Sampath TK, Hauschka PV. Human osteogenic protein-1 induces chondroblastic, osteoblastic, and/or adipocytic differentiation of clonal murine target cells. Exp Cell Res. 1996;222:38-47. doi:10.1006/excr.1996.0005

14. Ristiniemi J, Flinkkila T, Hyvonen P, Lakovaara M, Pakarinen H, Jalovaara P. RhBMP-7 accelerates the healing in distal tibial fractures treated by external fixation. J Bone Joint Surg Br. 2007;89:265-272. doi:10.1302/0301-620X.89B2.18230

15. Hogan BL. Bone morphogenetic proteins: multifunctional regulators of vertebrate development. Genes Dev. 1996;10(13):1580-1594. doi:10.1101/gad.10.13.1580

16. Thiery JP, Acloque H, Huang RY, Nieto MA. Epithelial-mesenchymal transitions in development and disease. Cell. 2009;139(5):871890. doi:10.1016/j.cell.2009.11.007

17. Thiery JP. Epithelial-mesenchymal transitions in tumour progression. Nat Rev Cancer. 2002;2(6):442-454. doi:10.1038/nrc822

18. Na YR, Seok SH, Kim DJ, et al. Bone morphogenetic protein 7 induces mesenchymal-to-epithelial transition in melanoma cells, leading to inhibition of metastasis. Cancer Sci. 2009;100(11):22182225. doi:10.1111/j.1349-7006.2009.01301.x

19. Alarmo EL, Parssinen J, Ketolainen JM, Savinainen K, Karhu R, Kallioniemi A. BMP7 influences proliferation, migration, and invasion of breast cancer cells. Cancer Lett. 2009;275:35-43. doi: $10.1016 /$ j.canlet.2008.09.028

20. Masuda H, Fukabori Y, Nakano K, Takezawa Y, CSuzuki T, Yamanaka H. Increased expression of bone morphogenetic protein-7 in bone metastatic prostate cancer. Prostate. 2003;54:268-274. doi:10.1002/pros.10193

21. Xu G, Tang S, Yang J, et al. BMP7 expression in esophageal squamous cell carcinoma and its potential role in modulating metastasis. Dig Dis Sci. 2013;58:1871-1879. doi:10.1007/s10620-013-2611-3

22. Cheng L, Lu W, Kulkarni B, et al. Analysis of chemotherapy response programs in ovarian cancers by the next generation sequencing technologies. Gynecol Oncol. 2010;117(2):159-169. doi:10.1016/j.ygyno.2010.01.041

23. Yang X, Li D, Cheng S, et al. The correlation of bone morphogenetic protein 2 with poor prognosis in glioma patients. Tumor Biol. 2014;35:11091-11095. doi:10.1007/s13277-014-2424-9

24. Feng M, Li J, Wang J, et al. High glucose increases LPS-induced DC apoptosisthrough modulation of ERK1/2, AKT and Bax/Bcl-2. BMC Gastroenterol. 2014;14:98. doi:10.1186/1471-230X-14-98

25. Lamouille S, Jian X, Derynck R. Molecular mechanisms of epithelial-mesenchymal transition. Nat Rev Mol Cell Biol. 2014;15(3):178196. doi: $10.1038 / \mathrm{nrm} 3758$ 
26. Sieber C, Kopf J, Hiepen C, Knaus P. Recent advances in BMP receptor signaling. Cytokine Growth Factor Rev. 2009;20:343-355. doi:10.1016/j.cytogfr.2009.10.007

27. Wagner DO, Sieber C, Bhushan R, Borgermann JH, Graf D, Knaus P. BMPs: from bone to body morphogenetic proteins. Sci Signa. 2010;3 (107):mr1.

28. Arber N, Hibshoosh H, Moss SF, et al. Increased expression of cyclin D1 is an early event in multistage colorectal carcinogenesis. Gastroenterology. 1996;110:669-674. doi:10.1053/gast.1996.v110. pm8608874

29. Hunter T, Pines J. Cyclins and cancer. II: cyclin D and CDK inhibitors come of age. Cell. 1994;79(4):573-582. doi:10.1016/0092-8674 (94)90543-6

30. Kalluri R, Weinberg RA. The basics of epithelial-mesenchymal transition. J Clin Invest. 2009;119:1420-1428. doi:10.1172/JCI39104

31. Kong D, Li Y, Wang Z, Sarkar FH. Cancer stem cells and Epithelialto-Mesenchymal Transition (EMT)-phenotypic cells: are they cousins or twins? Cancers (Basel). 2011;3(1):716-729. doi:10.3390/ cancers30100716

32. Bailey JM, Singh PK, Hollingsworth MA. Cancer metastasis facilitated by developmental pathways: sonic hedgehog, notch, andbone morphogenic proteins. J Cell Biochem. 2007;102(4):829-839. doi: $10.1002 /$ jcb. 21509

33. Camara-Clayette V, Koscielny S, Roux S, et al. BMP7 expression correlates with secondary drug resistance in mantle cell lymphoma. PLoS One. 2013;8(9):e73993. doi:10.1371/journal.pone.0073993

34. Yin J, Jung JE, Choi SI, et al. Inhibition of BMP signaling overcomes acquired resistance to cetuximab in oral squamous cell carcinomas. Cancer Lett. 2018;414:181-189. doi:10.1016/j.canlet.2017.11.013

35. Benezra R, Davis RL, Lockshon D, Turner DL, Weintraub H. The protein Id: a negative regulator of helix-loop-helix DNA binding proteins. Cell. 1990;61(1):49-59. doi:10.1016/0092-8674(90) 90214-y
36. Ohashi-Ito K, Fukuda H. Functional mechanism of bHLH complexes during early vascular development. Curr Opin Plant Biol. 2016;33:42-47. doi:10.1016/j.pbi.2016.06.003

37. Hara E, Yamaguchi T, Nojima H, et al. Id-related genes encoding helix-loop-helix proteins are required for G1 progression and are repressed in senescent human fibroblasts. J Biol Chem. 1994;269 (3):2139-2145.

38. Miyazono K, Miyazawa K. Id: a target of BMP signaling. Sci.STKE. 2002;2002(151):pe40.

39. Liu Y, Pandey PR, Sharma S, et al. ID2 and GJB2 promote early-stage breast cancer progression by regulating cancer stemness. Breast Cancer Res Treat. 2019;175(1):77-90. doi:10.1007/s10549-018-05126-3

40. Liu Z, Yang J, Ge C, et al. Inhibitor of binding/differentiation 2 (Id2) is regulated by $\mathrm{CCAAT} /$ enhancer-binding protein- $\alpha(\mathrm{C} / \mathrm{EBP} \alpha)$ and promotes the proliferation of hepatocellular carcinoma. Am J Cancer Res. 2018;8(11):2254-2266.

41. Kamata YU, Sumida T, Kobayashi Y, Ishikawa A, Kumamaru W, Mori Y. Introduction of ID2 enhances invasiveness in ID2-null oral squamous cell carcinoma cells via the SNAIL axis. Cancer Genomics Proteomics. 2016;13(6):493-497. doi:10.21873/cgp.20012

42. Yokota Y, Mori S. Role of Id family proteins in growth control. J Cell Physiol. 2002;190(1):21-28. doi:10.1002/jcp.10042

43. Zhou JD, Ma JC, Zhang TJ, et al. High bone marrow ID2 expression predicts poor chemotherapy response and prognosis in acute myeloid leukemia. Oncotarget. 2017;8(54):91979-91989. doi:10.18632/ oncotarget.20559

44. Bae WJ, Koo BS, Lee SH, et al. Inhibitor of DNA binding 2 is a novel therapeutic target for stemness of head and neck squamous cell carcinoma. Br J Cancer. 2017;117(12):1810-1818. doi:10.1038/bjc.2017.373

45. Zhao Z, He H, Wang C, et al. Downregulation of Id2 increases chemosensitivity of glioma. Tumor Biol. 2015;36(6):4189-4196. doi:10.1007/s13277-015-3055-5

\section{Publish your work in this journal}

OncoTargets and Therapy is an international, peer-reviewed, open access journal focusing on the pathological basis of all cancers, potential targets for therapy and treatment protocols employed to improve the management of cancer patients. The journal also focuses on the impact of management programs and new therapeutic agents and protocols on patient perspectives such as quality of life, adherence and satisfaction. The manuscript management system is completely online and includes a very quick and fair peer-review system, which is all easy to use. Visit http://www.dovepress.com/ testimonials.php to read real quotes from published authors. 